\title{
EFEKTIVITAS PELAKSANAAN FUNGSI LEGISLASI DPRD BABEL PERIODE 2009-2014
}

\author{
Bambang Ari Satria \\ STISIPOL PAHLAWAN 12, Jl. Diponegoro No. 16 Bangka 33215 \\ Telp/Fax. 0717-92750 \\ Surel: bambang_ari_satria@yahoo.com
}

\begin{abstract}
ABSTRAK
Penelitian ini berjudul Efektivitas Pelaksanaan Fungsi Legislasi Dewan Perwakilan Rakyat Daerah (DPRD) Bangka Belitung Periode 2009-2014. Tujuan penelitian ini adalah untuk menjelaskan efektivitas pelaksanaan fungsi legislasi DPRD Babel Periode 2009-2014. Hasil penelitian ini menunjukkan bahwa pelaksanaan fungsi legislasi DPRD Babel Periode 2009-2014 kurang efektif. Upaya-upaya untuk pengefektivitasan pelaksanaan fungsi legislasi adalah harus ada mekanisme baku dalam menyelesaikan Raperda, penambahan dan peningkatan sumber daya manusia pendukung, memperkuat koordinasi dengan alat kelengkapan lain sehingga kedudukan badan legislasi sebagai pusat pembentukan Raperda berjalan efektif.
\end{abstract}

Kata kunci: Efektivitas; Fungsi Legislasi

\begin{abstract}
This study entitled The Effectiveness of Legislative Function Implementation ofRegional Representative Council (DPRD) of Bangka Belitung, Period of 2009 to 2014. The purpose of this study is to explain the effectiveness of the implementation of the legislative function of regional representatives council (DPRD) of Bangka Belitung, period of 2009 to 2014. The results of this study indicated that the implementation of the legislative function regional representatives council (DPRD) of Bangka Belitung, period of 2009 to 2014 has not been effective yet. Efforts to streamline the implementation of the legislative function is by providing the mechanism standard in completing the legislation draft, additing and improving the human resources in the implementation of the legislative function, strengthening coordination with other fittings so that the position of the legislative board as the center of Raperda maker of legislation draft can be effective.
\end{abstract}

Keywords: Effectiveness; Legislative function 


\section{PENDAHULUAN}

Tolok ukur utama untuk menilai bagaimana efektifnya suatu pemerintahan adalah dengan melihat efektivitas kebijakan publik, baik menyangkut perumusan maupun implementasinya (Kumorotomo, 2008). Kebijakan publik adalah suatu kesepakatan yang diperoleh melalui proses politik yang mendesak di dalam masyarakat. Pada umumnya, rumusan dan arah kebijakan publik dapat diketahui dari produk undang-undang.

Berdasarkan pasal 19 Ayat 2 UU Nomor 32 Tahun 2004 tentang Pemerintah Daerah, penyelenggaraan pemerintahan adalah pemerintah daerah dan Dewan Perwakilan Rakyat Daerah (DPRD). Dalam penjelasan umum dapat diambil suatu makna pemisahan Pemerintahan Daerah (Eksekutif) dengan Dewan Perwakilan Rakyat Daerah (Legislatif) adalah untuk memberdayakan Dewan Perwakilan Rakyat Daerah dan meningkatkan pertanggungjawaban pemerintahan kepada rakyat. Sebagai legislatif daerah, Dewan Perwakilan Rakyat Daerah mempunyai fungsi sebagaimana tercantum dalam Penjelasan Umum Undang-Undang Nomor 32 Tahun 2004 Pasal 41 menyebutkan bahwa DPRD memiliki fungsi antara lain: (a) fungsi legislasi, (b) fungsi pengawasan, dan (c) fungsi anggaran.

Salah satu fungsi penting DPRD dalam rangka mendukung pelaksanaan otonomi luas di daerah adalah fungsi legislasi. Fungsi legislasi merupakan bagian dari proses politik kebijakan. Proses politik kebijakan adalah sebuah proses yang melegitimasi kebijakan publik sebagai solusi masalah publik dengan menyandarkan pada proses pembahasan kebijakan di lembaga politik yang diakui sebagai representatif publik (Indiahono, 2009). Kebijakan publik yang akan dilegitimasi dalam fungsi legislasi adalah peraturan daerah.

Dalam pembuatan dan perancangan peraturan daerah sebagai implementasi fungsi legislasi tersebut, DPRD tidak hanya bekerja sendiri melainkan merancang peraturan daerah tersebut bersama kepala daerah dalam hal ini gubernur untuk mendapatkan persetujuan bersama (UU Nomor 32 Tahun 2004 Pasal 42 Ayat 1 Poin a). Rancangan peraturan daerah dapat berasal dari DPRD, gubernur, atau bupati/ wali kota. Selanjutnya, rancangan peraturan daerah harus mendapat persetujuan bersama DPRD dan gubernur atau bupati/ walikota untuk dapat dibahas lebih lanjut. Tanpa persetujuan bersama, rancangan tersebut tidak akan dibahas. Pada praktiknya, akibat penggunaan model desentralisasi berkeseimbangan, perlu ada perubahan pembagian peran antara kepala daerah dan DPRD. Salah satu perubahannya adalah mengenai fungsi pengaturan yang selama ini lebih banyak didominasi oleh kepala daerah. Padahal fungsi tersebut seharusnya lebih banyak menjadi ranah DPRD, sehingga tercapai prinsip "check and balance" antara kepala daerah dan DPRD. Permasalahan diatas juga dirasakan oleh DPRD Babel.

Kabul (2004), mengutip kesimpulan penelitian LIPI dan LAN, menyatakan bahwa dalam era reformasi ini pada umumnya fungsi legislasi di daerah mengalami kelemahan yang dikarenakan beberapa faktor. Faktor tersebut adalah sebagian besar inisiatif peraturan daerah datang dari pihak eksekutif, kualitas Perda masih belum optimal sebab kurang mempertimbangkan dampak ekonomis, sosial, dan politis secara mendalam, dan kurangnya pemahaman terhadap permasalahan daerah.

Peraturan daerah yang menjadi target dalam Prolegda secara dominan merupakan usulan dari pemerintah Provinsi Babel, padahal fungsi dalam menjalankan legislasi seutuhnya milik legislatif, dalam hal ini DPRD Provinsi Babel. Minimnya Perda yang menjadi hak inisiasi legislatif menandakan adanya permasalahan konseptual (conseptual problems) dalam pelaksanaan fungsi 
legislasi yang dilakukan oleh Dewan Perwakilan Rakyat Daerah (DPRD) Provinsi Kepulauan Bangka Belitung Periode 2009-2014.

Proses penyusunan Perda adalah rangkaian kegiatan penyusunan produk hukum daerah sejak dari perencanaan sampai dengan penetapan. Secara umum proses pembentukan perda terdiri dari 3 (tiga) tahap, yaitu:

1. Proses penyiapan rancangan Perda yang merupakan proses penyusunan dan perancangan di lingkungan DPRD atau di lingkungan Pemda, terdiri penyusunan naskah akademik dan naskah rancangan Perda.

2. Proses mendapatkan persetujuan, yang merupakan pembahasan di DPRD.

3. Proses pengesahan oleh kepala daerah dan pengundangan oleh sekretaris daerah.

Penyusunan naskah akademik yang baik akan sangat membantu kedalaman substansi rancangan peraturan perundang-undangan yang akan disusun (Masitah, 2013: 110). Untuk itu, penyusunan naskah akademik harus didukung dengan bahan penunjang berupa data dan informasi akurat, yang diperoleh dari hasil pengkajian dan penelitian (baik penelitian hukum maupun non-hukum), disertai dengan analisis dan evaluasi peraturan perundang-undangan yang berlaku dan peraturan terkait.

Adapun data tentang hak inisiatif DPRD Babel maupun usulan Pemerintah Provinsi Babel dalam pembuatan Perda dapat dilihat pada Tabel 1 di bawah ini:

Tabel 1. Data Raperda Inisiatif DPRD dan Usulan Pemprov Babel

\begin{tabular}{cccc}
\hline No. & Tahun & Inisiatif DPRD & Usuluan Pemprov \\
\hline 1. & 2010 & 5 & 22 \\
\hline 2. & 2011 & 3 & 12 \\
\hline 3. & 2012 & 11 & 15 \\
\hline 4. & 2013 & 11 & 15 \\
\hline 5. & 2014 & 13 & 17 \\
\hline
\end{tabular}

Sumber data: Sekretariat DPRD Babel

(data diolah)

Berdasarkan Tabel 1 di atas, DPRD Babel yang merupakan wakil rakyat seharusnya menjadi sumber inisiatif, ide dan konsep mengenai berbagai peraturan daerah yang akan mengikat masyarakat, sebab merekalah yang seharusnya mengetahui secara tepat kebutuhan dan keinginan masyarakat. Sehingga melahirkan suatu peraturan yang memihak pada rakyat dan tidak merugikan rakyat. Oleh sebab itu, diperlukan peningkatan fungsi legislasi DPRD Babel yang tidak hanya dilihat dari jumlah peraturan daerah yang dihasilkan, tetapi juga berasal dari hak inisiatif DPRD Provinsi Babel. Kualitas DPRD dalam menjalankan fungsi ini juga diukur dari muatan peraturan daerah yang seharusnya lebih banyak berpihak kepada kepentingan masyarakat luas.

Adapun target dan realisasi produk legislasi yang dilaksanakan oleh DPRD Babel periode 2009-2014 dapat dilihat pada Tabel 2 di bawah ini: 
Tabel 2. Data Target dan Realisasi Produk Legislasi DPRD Babel 2009-2014

\begin{tabular}{cccc}
\hline No. & Tahun & Target RAPERDA & Realisasi RAPERDA \\
\hline 1. & 2010 & 27 & 12 \\
\hline 2. & 2011 & 15 & 7 \\
\hline 3. & 2012 & 26 & 5 \\
\hline 4. & 2013 & 26 & 8 \\
\hline 5. & 2014 & 30 &
\end{tabular}

Sumber data: Sekretariat DPRD Babel

(data diolah)

Tabel 2 menyebutkan bahwa penyelesaian Raperda dalam fungsi legislasi dari tahun 2010 sampai tahun 2014 tidak pernah mencapai target yang telah ditetapkan. Pelaksanaan fungsi legislasi DPRD Babel periode 2009-2014 belum maksimal bahkan dibatasi terutama dalam melaksanakan hak inisiatif dalam pembentukan peraturan daerah. Misalnya dalam memberikan masukan tentang tata ruang wilayah. Dalam hal ini masukan tentang rencana tata ruang wilayah ingin didominasi oleh Pemerintah Provinsi Babel dan menginginkan pembuatan Raperdanya berasal dari Pemprov Babel sehingga telah dibentuk Panja khusus yang akan menyusun Raperda tersebut. Penulis menilai fungsi legislasi anggota DPRD Babel periode 2009-2014 belum maksimal sebab tak bisa ditampik bahwa menginisiasi dan merumuskan draf legislasi adalah pekerjaan akademik dan membutuhkan pemikiran yang serius dan relatif rumit.

\section{METODE}

Penelitian ini adalah penelitian yang fokus membahas bagaimana efektivitas pelaksanaan fungsi legislasi DPRD Babel Periode 2009-2014. Metode penelitian yang digunakan dalam penelitian ini adalah penelitian kualitatif dengan teknik analisis deskriptif. Sumber data yang digunakan berupa sumber data yang berasal dari teks berupa buku, jurnal, dan laporan kerja badan legislasi sesuai dengan permasalahan penelitian.

\section{PEMBAHASAN}

Perumusan kebijakan merupakan tahap penting dalam proses suatu kebijakan publik. Perumusan kebijakan perlu dilakukan untuk membuat kebijakan publik. Perumusan dilaksanakan untuk mengetahui seberapa jauh suatu produk kebijakan dapat membuahkan hasil, yaitu dengan membandingkan antara hasil yang diperoleh dengan tujuan atau target yang ditentukan. Perumusan kebijakan yang dibahas adalah pelaksanaan fungsi legislasi DPRD Babel Periode 20092014.

Untuk melihat pelaksanaan fungsi legislasi DPRD Babel dilakukan dalam beberapa aspek sesuai dengan model teori sistem dalam perumusan kebijakan yang digunakan. Aspek yang dilakukan dalam penelitian meliputi aspek input yang memberikan informasi penggunaan sumber daya yang tersedia. Aspek proses, memberikan informasi mengenai proses pelaksanaan. Aspek output, yang memberikan informasi mengenai hasil dari pelaksanaan. 


\section{Aspek Input}

Aspek input berkaitan dengan masalah kebijakan publik yang timbul karena adanya faktor lingkungan kebijakan publik yaitu suatu keadaan yang melatarbelakangi atau peristiwa yang menyebabkan timbulnya masalah kebijakan publik tersebut, yang berupa tuntutan-tuntutan dan keinginan masyarakat yang diharapkan segera diatasi melalui suatu kebijakan publik. Dalam aspek ini akan dilihat bagaimana kekuatan lingkungan eksternal dan internal, kapabilitas pembuat legislasi, dukungan stakeholder dan model pembangunan masyarakat Babel.

Aspek input dalam pelaksanaan fungsi legislasi DPRD Babel sangat penting dikarenakan adanya kapabilitas pembuat legislasi yang termasuk ke dalam aspek ini. Aspek input menentukan dalam keberhasilan pelaksanaan fungsi legislasi di DPRD Babel. Hasil temuan lapangan pada aspek input dapat dilihat pada Tabel 3 di bawah ini:

Tabel 3. Temuan Lapangan Pada Aspek Input

\begin{tabular}{|c|c|}
\hline Fokus Kajian & Temuan Lapangan \\
\hline 1. Kekuatan Lingkungan Eksternal Internal & $\begin{array}{l}\text { Adanya kekuatan lingkungan eskternal } \\
\text { dan internal dalam pelaksanaan fungsi le- } \\
\text { gislasi, tetapi belum berjalan secara efektif. }\end{array}$ \\
\hline 2. Kapabilitas Pembuat Legislasi & $\begin{array}{l}\text { Kapabilitas pembuat legislasi cukup baik, } \\
\text { tetapi tidak didukung oleh sumber daya } \\
\text { manusia lainnya yang mengerti fungsi le- } \\
\text { gislasi. Misalnya pengadaan tenaga ahli. }\end{array}$ \\
\hline 3. Dukungan Stakeholder & $\begin{array}{l}\text { Keterlibatan stakeholder dalam pelaksana- } \\
\text { an fungsi legislasi cukup maksimal. Setiap } \\
\text { Raperda yang dibahas selalu melibatkan } \\
\text { stakeholder terkait. }\end{array}$ \\
\hline 4. Model Pembangunan Masyarakat Babel & $\begin{array}{l}\text { Model pembangunan masyarakat Babel } \\
\text { telah terakomodasi dalam Perda Nomor } \\
06 \text { Tahun } 2012 \text { tengang Rencana Pemba- } \\
\text { ngunan Jangka Menengah (RPJM) Dae- } \\
\text { rah Provinsi Kepulauan Babel 2012-2017. }\end{array}$ \\
\hline
\end{tabular}

Sumber: diolah dari data primer

Berdasarkan Tabel 3 tersebut tentang temuan lapangan pada aspek input menyimpulkan bahwa fokus kajian pada kekuatan lingkungan internal dan eksternal sudah ada dalam pelaksanaan fungsi legislasi DPRD Babel, tetapi belum efektif. Ini dibuktikan dengan pembuatan naskah akademik yang melibatkan pihak Institut Pemerintahan Dalam Negeri (IPDN). Seharusnya kekuatan internal di Bangka Belitung layak untuk membuat naskah akademik seperti tim akademisi yang ada di Universitas Bangka Belitung (UBB). Apalagi menyangkut naskah akademik tentang Raperda Adat yang lebih mengedepankan aspek kearifan lokal dalam pembuatannya. Ditambah pula UBB memiliki Prodi Sosiologi di bawah naungan Fakultas Ilmu Sosial dan Ilmu Politik (FISIP) UBB yang bisa mengkaji dari unsur sosiologis. 
Dalam fokus kajian kapabilitas pembuat legislasi, disimpulkan bahwa kapabilitas pembuat legislasi cukup baik, tetapi belum didukung oleh tenaga pendukung seperti pengadaan tenaga ahli yang direkrut secara profesional, bukan karena kedekatan partai politik, sehingga kualitasnya benar-benar mampu untuk membantu anggota dewan dalam menjalankan fungsi legislasi. Belum terpenuhinya tenaga ahli dan staf ahli bagi anggota DPRD Provinsi Kepulauan Bangka Belitung merupakan hasil identifikasi permasalahan, tantangan serta potensi pemerintahan yang ada di DPRD Provinsi Kepulauan Bangka Belitung sebagaimana tertuang dalam rencana strategis (Renstra) Sekretariat DPRD Provinsi Kepulauan Bangka Belitung Tahun 2012-2017.

Dalam fokus kajian dukungan stakeholder, setiap Raperda yang dibahas dalam melaksanakan fungsi legislasi DPRD Provinsi Kepulauan Bangka Belitung selalu melibatkan stakeholder yang terkait sesuai dengan muatan Perdanya. Sedangkan model pembangunan masyarakat sudah diatur dalam produk hukum lokal, yakni Perda Nomor 06 Tahun 2012 tentang Rencana Jangka Pembangunan Menengah (RPJM) Daerah Provinsi Kepulauan Bangka Belitung Tahun 2012-2017. Aspek input dalam pelaksanaan fungsi legislasi DPRD Provinsi Kepulauan Bangka Belitung Periode 2009-2014 ini menentukan sumber-sumber daya yang ada, alternatif yang diambil, apa rencana dan strategi untuk mencapai kebutuhan. Jadi, dalam pelaksanaan fungsi legislasi DPRD Provinsi Kepulauan Bangka Belitung periode 2009-2014, sesuai dengan model teori sistem dimana pada aspek input digunakan untuk menjawab pertanyaan "how should we do it?" yaitu dengan mengoptimalkan semua sumber daya yang ada walaupun di lapangan masih ada keterbatasan. Dengan demikian DPRD Provinsi Kepulauan Bangka Belitung semaksimal mungkin menggunakan sumber daya yang ada untuk mencapai tujuan yang ditetapkan.

\section{Aspek Proses}

Aspek proses ini merupakan tahap yang dirancang dan diaplikasikan dalam pelaksanaan fungsi legislasi. Setelah instansi/ badan yang menginisiasi memahami prinsip-prinsip pembentukan Rancangan Peraturan Daerah, maka instansi tersebut telah siap untuk membuat kerangka konseptual dan memulai proses pembentukan Rancangan Peraturan Daerah. Pada intinya, pembentukan Rancangan peraturan daerah sebenarnya merupakan satu bentuk pemecahan masalah yang rasional.

Aspek proses dalam pelaksanaan fungsi legislasi DPRD Provinsi Kepulauan Bangka Belitung akan dilihat: program legislasi daerah.

Dalam aspek initerdapat keterkaitan fokus kajian dalam aspek proses. Keterkaitan ini dikarenakan di dalam aspek proses ini dilakukan kegiatan yang sudah direncanakan, tentang seberapa efektif pelaksanaan fungsi legislasi DPRD Provinsi Kepulauan Bangka Belitung Periode 2009-2014. Dalam aspek proses ini juga dapat diketahui apakah pelaksanaan sudah sesuai dengan apa yang telah direncanakan. Hasil temuan lapangan pada aspek proses dapat dilihat pada Tabel 4 berikut ini: 
Tabel 4. Temuan Lapangan Pada Aspek Proses

\begin{tabular}{|c|c|}
\hline Fokus Kajian & Temuan Lapangan \\
\hline Program Legislasi & Secara keseluruhan, DPRD Provinsi Kepulauan Bangka Belitung \\
\hline Daerah (Prolegda) & $\begin{array}{l}\text { Periode } 2009-2014 \text { sudah menyusun program legislasi daerah, } \\
\text { baik itu raperda inisiatif dewan maupun Raperda usulan peme- } \\
\text { rintah provinsi.. }\end{array}$ \\
\hline
\end{tabular}

Sumber: diolah dari data primer.

Tabel 4 menjelaskan bahwa DPRD Babel periode 2009-2014 telah menetapkan program legislasi daerah (Prolegda) per tahun anggaran mulai dari tahun 2010 sampai dengan tahun 2014. Prolegda yang ditetapkan terdiri dari Raperda inisiatif dewan dan Raperda usulan pemerintah Provinsi Kepulauan Bangka Belitung. Aspek proses ini digunakan untuk menilai pelaksanaan rencana dan membantu pelaksana dalam melaksanakan fungsi legislasi. Oleh karena itu, di dalam aspek proses ini dilaksanakan program legislasi daerah.

\section{Aspek Output}

\section{Strategi Peningkatan Kesejahteraan Masyarakat Babel}

Strategi peningkatan kesejahteraan masyarakat adalah cara yang dilakukan dalam sebuah kegiatan untuk membuat perbaikan dalam hal kemakmuran yang dirasakan oleh masyarakat dalam menjalankan usaha, dimana usaha tersebut dapat meningkatkan taraf kehidupannya dari pendapatan yang diperoleh dari usaha. Strategi peningkatan kesejahteraan tersebut akan memengaruhi pembangunan daerah. Masalah pokok dalam pembangunan daerah terletak pada penekanan terhadap kebijakan-kebijakan pembangunan yang didasarkan pada kekhasan daerah yang bersangkutan (endogeneous development) dengan menggunakan potensi sumberdaya manusia, kelembagaan dan sumber daya fisik secara lokal (daerah). Orientasi ini mengarahkan kita kepada pengambilan inisiatif-insisatif yang berasal dari daerah tersebut dalam proses pembangunan untuk menciptakan kesempatan kerja baru dan merangsang peningkatan kegiatan ekonomi.

\section{Hasil Legislasi yang Dicapai}

Hasil legislasi yang dicapai adalah menetapkan Raperda yang telah dibahas bersama DPRD Babel menjadi Perda. Kekuasaan legislatif menetapkan Raperda menjadi Perda bukan sesuatu kekuasaan mandiri, melainkan bagian dari proses membentuk Perda. Namun demikian, proses penetapan ini sangat penting sebagai perubahan Raperda menjadi Perda.

Sejak saat itulah Raperda lahir dan menjadi kaidah hukum walaupun telah menjadi kaidah hukum belum serta merta mengikat. Sebagai persyaratan mengikat masih diperlukan syarat lain yaitu dimuat dalam Lembaran Daerah. Pengesahan sebagai bentuk pengawasan preventif merupakan kelaziman dalam sistem otonomi di manapun juga.

Aspek output dalam pelaksanaan fungsi legislasi DPRD Provinsi Kepulauan Bangka Belitung dilakukan untuk melihat sejauh mana target legislasi dicapai. Hasil temuan lapangan pada aspek outputdapat dilihat pada Tabel 5., berikut. 
Tabel 5. Temuan Lapangan pada Aspek Output

\begin{tabular}{ll}
\hline \multicolumn{1}{c}{ Fokus Kajian } & \multicolumn{1}{c}{ Temuan Lapangan } \\
\hline Strategi peningkatan & Adanya Raperda yang mengatur tentang peningkatan kese- \\
kesejahteraan masyarakat & jahteraan masyarakat Babel, yakni Raperda APBD, APBD \\
Babel & $\begin{array}{l}\text { Perubahan, Raperda tentang pengelolaan dana CSR, dan } \\
\text { Raperda Pengelolaan Perkebunan Kelapa Sawit Pola Kemi- } \\
\\
\text { traan. }\end{array}$ \\
\hline Hasil legislasi yang dicapai & Hasil legislasi yang dicapai oleh DPRD Provinsi Kepulauan \\
& Bangka Belitung Periode 2009-2014 tidak pernah tercapai. \\
\hline
\end{tabular}

Sumber: diolah dari data primer.

Tabel 5 di atas menunjukkan bahwa DPRD Provinsi Kepulauan Bangka Belitung periode 2009-2014 dalam fokus kajian peningkatan kesejahteraan masyarakat Babel dituangkan dalam Raperda APBD, APBD Perubahan, Raperda CSR, dan Raperda Pengelolaan Perkebunan Kelapa Sawit Pola Kemitraan. Sedangkan dalam fokus kajian hasil legislasi yang dicapai, DPRD Provinsi Kepulauan Bangka Belitung tidak pernah mencapai target dari yang ditetapkan.

Sesuai dengan model sistem dalam perumusan kebijakan publik yang terdiri dari aspek input, proses, dan output, dimana ketiga aspek ini memiliki saling keterkaitan. Tiga aspek dalam model sistem perumusan kebijakan publik ini digunakan untuk membantu peneliti dalam menjawab pertanyaan dasar mengenai: 1) apa yang harus dilakukan, 2) bagaimana melaksanakannya, dan 3) apakah dikerjakan sesuai dengan rencana.

Dalam aspek input, dibahas mengenai bagaimana lingkungan internal dan eksternal mendukung dalam pembuatan produk legislasi, dukungan stakeholder yang terkait, dan kapabilitas pembuat legislasi dalam menjalankan fungsi legislasi di DPRD Provinsi Kepulauan Bangka Belitung. Dari hasil penelitian diketahui bahwa lingkungan internal dan eksternal belum mampu memberikan kontribusi secara menyeluruh dalam pelaksanaan fungsi legislasi, kapabilitas pembuat legislasi tidak maksimal.

Dengan diketahui bahwa ada dukungan lingkungan internal dan eksternal, kapabilitas pembuat legislasi, dan dukungan stakeholder pada aspek input, maka ini sangat memengaruhi terhadap program legislasi daerah. Pada aspek proses inilah diatur mengenai program legislasi daerah yang dipakai untuk melaksanakan fungsi legislasi yang dijadikan target dalam pelaksanaannya. Aspek ini diidentifikasikan sebagai salah satu permasalahan yang ada dalam pelaksanaan fungsi legislasi adalah Progleda yang disusun hanya berdasarkan keinginan atau judul, tetapi tidak dilengkapi dengan naskah akademis dan draf Raperda.

Aspek selanjutnya adalah aspek output dimana pada aspek ini digunakan untuk menilai ketercapaian produk legislasi yang telah disusun melalui program legislasi daerah (Prolegda) apakah sesuai dengan target yang telah ditetapkan hasil legislasi yang dicapai oleh DPRD Provinsi Kepulauan Bangka Belitung belum sesuai dengan apa yang menjadi target. Jadi, pelaksanaan fungsi legislasi Dewan Perwakilan Rakyat Daerah (DPRD) Provinsi Kepulauan Bangka Belitung Periode 2009-2014 tidak efektif. 


\section{KESIMPULAN}

Berdasarkan hasil pembahasan tentang efektivitas pelaksanaan fungsi legislasi DPRD Babel periode 2009-2014, maka dapat disimpulkan bahwa pelaksanaan fungsi legislasi DPRD Babel periode 2009-2014 belum efektif. Aspek Input, yang meliputi kekuatan lingkungan eksternal dan internal, kapabilitas pembuat legislasi, dukungan stakeholder, dan model pembangunan masyarakat Babel belum tersinkronisasi dengan baik. Kekuatan lingkungan eksternal dan internal dalam pembentukan Raperda di DPRD Provinsi Kepulauan Bangka Belitung belum berjalan secara efektif. Kapabilitas Pembuat legislasi belum optimal dalam pelaksanaan fungsi legislasi. Adanya dukungan stakeholder dan pembentukan Raperda menyesuaikan dengan kebutuhan pembangunan masyarakat Babel.Secara keseluruhan pelaksanaan fungsi legislasi dari aspek proses sudah efektif. Ini terlihat dari adanya Prolegda yang dibuat oleh DPRD Babel.Aspek Output, meliputi strategi peningkatan masyarakat babel dan hasil legislasi yang dicapai. Pencapaian hasil legislasi yang dilakukan oleh DPRD Babel melalui fungsi legislasi belum sesuai dengan target yang ditetapkan dalam Prolegda.

\section{DAFTAR PUSTAKA}

Indiahono, Dwiyanto. 2009. Kebijakan Publik Berbasis Dynamic Policy Analysis, Yogyakarta: Gavamedia.

Kabul, S. 2004. Peranan Asosiasi Dalam Peningkatan Kapasitas DPRD. Buletin YPOD, III (3), 1-2.

Kumorotomo, Wahyudi. 2008. Akuntabilitas Birokrasi Publik, Yogyakarta: Pustaka Pelajar. Masitah, Siti. 2013. Urgensi Naskah Akademik Dalam Pembentukan Peraturan Daerah. Jurnal LEGISLASI INDONESIA Vol. 10 No. 02 - Juni 2013 hlm: 109 - 122.

Undang-Undang Nomor 32 Tahun 2004 Tentang Pemerintah Daerah. Undang-Undang Nomor 23 Tahun 2014 Tentang Pemerintah Daerah 
